\title{
TAILORED MEDIA FOR THE DETECTION OF $E$. COLI AND COLIFORM IN THE WATER SAMPLE
}

\author{
Prof. Prahlad Raj Pant
}

\section{INTRODCUTION}

Water plays a significant role for the sound health of every person and is also essential for plant life. About $75 \%$ of the earth's crust is covered with water, and the human body comprises approximately $70 \%$ of water. So drinking water is most urgent for human life. In Nepal about $50 \%$ of the urban citizens are benefited from piped supply drinking water. Rest of the population have to rely on natural sources. Nepal is a land of many villages where the majority of the people are living. In rural areas of our country, pond, river, lake and stream which are situated several kilometres away from villages. They are the main sources of water. So in most of the villages the people have to go daily almost a kilometer for the search of drinking water as well as for cleaning purposes. They don't know whether the water is wholesome or not. There may be environmental pollution, which may result in the deterioration of water quality, which causes the outbreaks of many diseases.

Therefore, supply of potable water is essential for good health of human beings. In Europe and America much attention has been paid to the problem of water purity. This is obvious from the fact that in developed countries people are rarely attacked by water-borne diseases hence have better health than the people of developing countries. However, the people of developing countries including Nepal should fight against intestinal diseases. Water, which may appear pure to the nake eye, may contain organisms that promote diseases such as typhoid, cholera, dysentery, giardiasis, amocbiasis and infective hepatitis etc. These "impurities" may arise due to water contaimination by sewage or human and animal excreta or may result from inadequate treatment during distribution. This potential problem is one of great concern with drinking water.

\section{OBJECTIVE OF THE WATER TREATMENT}

The objective of the water treatment is to supply potable water that is chemically and microbiologically safe for human consumption. This purity can be achieved by a variety of processes depending upon the source and nature of the water. These processes include clarification, sedimentation, filtration and disinfections. The overall main aim of these procedures is to reduce the number of organisms present in the water and find an essential safeguard against waterborne microbial diseases. 


\section{TAILORED MEDIA FOR THE DETECTION}

\section{MICROBIAL QUALITY OF WATER}

Water is essential to support life and water authorities expend considerable time and effort to achieve a drinking water quality as high as practicable. Failure to recognise the importance of water quality exposes the population to the risk of diseases. The very young, the elderly, the sick and those who live in sub-standard sanitary condition (WHO, 1993) are particularly susceptible to water-borne diseases and microbial contamination remains a critical risk factor in drinking water (Fawell \& Miller, 1992) in many parts of the world.

Direction of specific pathogens in water supplies were difficult and largely impracticable (Bonde, 1977). The use of indicator organisms in particular the coliform group, as a means of assessing the presence of pathogens has been paramount in the approach to determine water quality as adopted by the World Health Organisation (WHO), United States Environment Protection Agency USEPA) and European Union (EU) EC, 1980; USEPA, 1992; WHO, 1993).

Thus an efficient and reliable method is required in order to achieve a test result within a few hours. On the other hand, the method must be simple and cost effective as well. Therefore the present work has been based on finding rapid method for the detection and enumeration of $E$. coli and coliform from new formulation protocol. The overall efforts was to recover the maximum number of E. coli in a short length of incubation time. So that particularly in emergencies the method could be used, when there is an urgent need to determine the quality of water.

\section{PUBLIC HEALTH SIGNIFICANCE}

Much of the world population remains without access to high quality potable water supplies and adequate sanitation (Table- 1) (Esrey \& Habicut, 1986). WHO estimates that $80 \%$ of all sickness in the world can be attributable to inadequate potable water supplies and poor sanitation (Morrison, 1983). There are many water borne pathogens now recognised and all may be in human and animal excreta in large numbers. Such pathogens are generally resistant to environmental decay, and many are capable of causing infections even when ingested in low concentrations.

There are three different groups of microorganism that can be transmitted by drinking water, these are viruses, bacteria, and protozoa.

The faecal-oral route transmits the species in the groups and so principally the associated diseases arise either directly or indirectly by contamination of water resources by sewage or possibly animal's wastes. It is theoretically possible, but unlikely that other pathogenic organisms such as roundworm, hookworm (Nematodes) and Tapeworm (Cestodes) may also be transmitted by drinking water (Gleeson \& Gray, 1997). The lists of common bacteria, viruses and protozoa and associated diseases are given below Table: 
TRIBHUVAN UNIVERSITY JOURNAL, VOL. XXIV, NO. 1,

Table- 1:

\begin{tabular}{|l|l|l|}
\hline \multicolumn{1}{|c|}{ Agent } & \multicolumn{1}{c|}{ Disease } & \multicolumn{1}{c|}{$\begin{array}{c}\text { Incubation } \\
\text { Time }\end{array}$} \\
\hline BACTERIA & & \multicolumn{1}{c|}{} \\
\hline Shigella spp & Bacelliary dysentery & $1-7$ days \\
\hline Salmonella spp & Gastro-enteritis & $6-72$ hrs. \\
\hline Salmonella typhi & Typhoid fever & $1-3$ days \\
\hline Enterotoxigenic & & \\
\hline Escherichia coli (Merge cells (ETEC) & Diarrhoea & $12-72$ hrs. \\
\hline Campylobacter spp & Gastro-enteritis & $1-7$ days \\
\hline Vibrio cholerae & Cholera & $1-3$ days \\
\hline VIRUSES & & $15-45$ days \\
\hline Hepatitis A and E & Hepatitis & $1-7$ days \\
\hline Norwalk-like agent & Gastro-enteritis & $1-7$ days \\
\hline Virus-like particles $<27 \mathrm{~nm}$ & Gastro-enteritis & $1-2$ days \\
\hline Rotavirus & $\begin{array}{l}\text { Gastro- } \\
\text { enteritis/Diarrhoea }\end{array}$ & \\
\hline PROTOZOA & & $7-10$ days \\
\hline Giardia lamblia & Giardiasis & $2-4$ weeks \\
\hline Entamoeba histolytica & Ameobic dysentery & $5-10$ days \\
\hline Cryptosporidium parvum & Cryptosporidiosis & \\
\hline Cydorspora ........ & & \\
\hline
\end{tabular}

Infections related to water may be classified into the four following main groups:

\section{WATER BORNE DISEASES}

This is where a pathogen is transmitted by ingestion of contaminated water. Cholera and typhoid fevers are the classical example of water borne diseases.

\section{WATER WASHED DISEASES}

These include faeco-orally spread diseases or diseases spread from one person to another facilitated by a lack of an adequate supply of water for washing. Many diarrhoea/diseases as well as diseases of the eyes and kin are transmitted in this way.

\section{WATER BASED INFECTIONS}

These diseases are caused by pathogenic organisms which spend part of their life cycle in aquatic organisms system.

\section{WATER RELATED DISEASES}

These diseases are caused by insect vectors which breed in water, these include mosquitoes which spread malaria and filariasis and arthropods which carry viruses such as those causing dengue and yellow fever. 


\section{TAILORED MEDIA FOR THE DETECTION}

\section{DEFINITION OF COLIFORM GROUP}

The coliform groups consist of several genera o f bacteria belonging to the family Enterobacteriaceae. Traditionally these genera include Escherichia, Citrobacter, Enterobacter and Klebsiella. However, using more modern taxonomic criteria, the group is more heterogeneous and includes non-faecal, lactose fermenting bacteria as well as other species which are rarely found in faeces but are capable of multiplication in water (WHO, 1993).

The definition of the coliform group has been based on methods used for its detection rather than on the tenets of systematic bacteriology (American Public Health Association (APHA, 1992). Accordingly, the APHA defines coliforms as "all aerobic and facultative anaerobic gram negative, non-spore forming, rod shaped bacteria that ferment lactose with acid gas production." The WHO definition is broader and refers to gram negative, rod-shaped bacteria capable of growth in the presence of bile salt or other surface active agent with similar growth inhibiting properties, able to ferment lactose at $37^{\circ} \mathrm{C}$ with production of gas and acids within 24-48 hrs. coliforms are oxidase negative, possess $\beta$ galactosidase and produce acid from lactose within $48 \mathrm{hrs}$. at $37^{\circ} \mathrm{C}$. Further identification may be carried out using characteristic colonies from Mac-conkey agar by means of appropriate biochemical and other tests (Cowan, 1993). Some non-coliform organisms such as Aeromonas spp also ferment lactose. The coliform group also includes the thermotolerent faecal coliforms. These are defined as being able to ferment lactose at $44^{\circ} \mathrm{C}$ (WHO, 1993) and not only include E.coli but also species of the Klebsiella, Enterobacter and Citrobacter genera. E. coli is considered to be the only true faecal coliform as other thermotolorent coliforms can be derived from non-faecal contaminated waters. $E$. coli is a member of the family Entrobacteraceae which produces acid and usually gas from lactose or mannitol at $44^{\circ} \mathrm{C}$ and which produces indole from tryptophan. Some strains are anaerogenic (non-gas producing) and most possess $\beta$ glucuronidase. Not all thermotolerant coliforms are faecal in origin (Department of the Environment,1993a). The presence of $E$. coli which is known to be exclusively faecalin origin is usually determined.

\section{ESCHERICHIA COLI (E. COLI) AND OTHER COLIFORMS ORGANISMS}

E. coli is the most abundant coliform organism present in the human and animal intestine and occurs in numbers approaching 1000 million per gram of fresh faeces. It is rarely found in sub tropical climates soil, vegetation or water in the absence of faecal contamination. Some samples of soils have been found to be completely free from coliforms. In contrast, small numbers of E. coli can occasionally be found in soil far removed from the possibility of faecal contamination by man and domestic animals also by wild animals and excreting birds (Reports on public health and medical subjects No. 71). Since E. coli and other coliform organisms are present in large numbers in faeces and sewage, they can be detected in numbers as small as 1 in $100 \mathrm{ml}$ of water. They are the most sensitive indicator bacteria for demonstrating feacal contamination. For this reason not only must coliform organisms including $E$. coli be detected, but 
TRIBHUVAN UNIVERSITY JOURNAL, VOL. XXIV, NO. 1,

estimation must also be made of their numbers in order to assess the degree of pollution and hence the danger to health.

\section{OBJECTIVE OF THE PROJECT}

In many remote areas of the world the contamination which renders water non-potable arises from bacterial contamination. In these regions, there is frequently inadequate testing facilities for water and hence a simple reliable method is required. There are other methods which may be used to detect these organisms but these methods do dectect this organism in a longer time. Thus a rapid method is required to dectect the indicator organisms and the present study is designed to investigate a detection method for these indicator organisms which can produce the completed analysis within 8 hourse or less.

A new medium has been proposed to analyse water microbiologically which is based on tailored made. The need is to detect and enumerate the coliforms and $E$. coli present in water samples within 8 hours or less, and also to determine the usefulness of this method as a routing procedure.

\section{MATERIALS AND METHODS}

\section{COLILERT METHOD}

The Colilert is based on IDEXX'S patented defined substrate technology $\left(\mathrm{DST}^{\mathrm{TM}}\right)$. It is designed for the detection and confimration of $E$. coli and coliforms and may be used in a presence-absence (P/A) or most probable number (MPN) format. Total coliforms produce the enzyme $\beta$-galactosidase which hydrolyses the indicator nutrient, o-nitrophenyl- $\beta$-D galactopyranoside (ONPG) and releases o-nitrophenol, to produce a yellow color. E. coli produces the enzyme $\beta$-glucuronidase which hydrolyses 4-methyl umbelliferyl- $\beta$-Dglucuronide (MUG) to form 4-methyl umbelliferone and this fluoresces under long wave UV light $(365 \mathrm{~nm})$. The $E$. coli and coliforms present in the sample metabolise the nutrient indicators and produces a yellow colour and fluorescence in UV light. The Colilert detects these bacteria at $1 \mathrm{cfu} / 100 \mathrm{ml}$ within 18 Hours with as many as 2 million heterotrophic bacteria/100 ml. All samplese which were yellow after 18 hours of incubation were examined under the UV light (365 $\mathrm{nm})$. Those samples which gave the characteristic fluorescence were identified as $E$. coli and those which were yellow and did not fluoresce were identified as coliforms. The most probable number (MPN) was calculated for each sample by using the MPN table. The method based on defined Substrate Technology using colilert-18 is widely applied in the United States of America for the detection of E. coli and coliforms and in the UK at several water utilities.

The test can be summarised as follows:

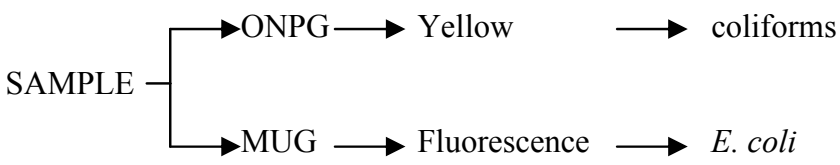




\section{TAILORED MEDIA FOR THE DETECTION}

\section{MEMBRANES}

In the present study, Gelman black and Gelman white membranes were used for the majority of the work. In one investigation Whatmann, Sartorius, Millipore and Corning membranes were examined. These were all $47 \mathrm{~mm}$ in diameter with a grid having a pore size of $0.45 \mu \mathrm{m}$. The grid markes on the membrane facilitated counting. It is important to ensure that the bacterial growth is neither inhibited nor stimulated along the grid lines. For microbiological use both black and white membranes were used in pre-sterilised condition. The pore size of the membrane is such that the microorganisms are retained on the surface of the membrane when samples were filtered. The membranes were transferred aseptically onto the medium. Nor air must be present between the membranes and the medium during the transference procedure.

\section{CYTOCHROME OXIDASE TEST}

This test was performed on all sub-cultures because any organism that displays cytochrome oxidase is excluded from the family Enterbacteriaceae. No coliforms including E. coli are oxidase positive while Aeromonas spp, Pseudomonas spp, and Campylobacter spp etc. show an oxidase positive reaction.

\section{INTERPRETATION OF TEST RESULTS}

(a) Beta- glactosidase: Negative

Beta- glucuronidase: Negative

Cytochrome Oxidase: Negative

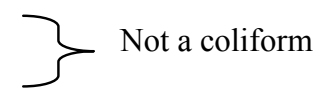

(b) Beta- galactosidase: Positive Beta- glucuronidase: Negative Cytochrome Oxidase: Negative

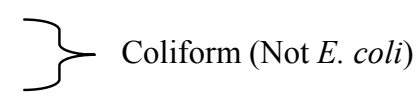

(c) Beta- galactosidase: Positve Beta- glucuronidase: Positive Cytochrome Oxidase: Negative

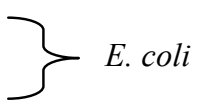

(d) Beta- galactosidase: Positive or Negative Beta- glucuronidase: Positive or Negative $\succ$ Not a coliform Cytochrome Oxidase: Positive

\section{GLASSWARE AND PLASTICWARE}

All glassware and plastic wares used in this project were sterilised by autoclave. A time-temperature combination of $121^{\circ} \mathrm{C}$ for 15 minutes which was specified for much microbiological purpose, was strictly followed during the experimental work.

The new media comprised the following ingredients:

Proteose opeptone

Yeast Extract

Sodium chloride

Pyruvate 
TRIBHUVAN UNIVERSITY JOURNAL, VOL. XXIV, NO. 1,

IPTG

MUGlue

MUGal

IPTG is isorpropyl- $\beta$-D-thiogalactopyranoside

MUGlue is 4-methylumbelliferyl- $\beta$-D-glucuronide

MUGal is 4-methylumbelliferyl- $\beta$-D-galactopyranoside

Following studies were made during the experiemental work:

1. Comparision of recovery of colonies on media comprising (Nacl 7.6 $\mathrm{gm} / \mathrm{L}$, IPTG $0.1 \mathrm{gm} / \mathrm{L}$ and MUG $0.1 \mathrm{gm} / \mathrm{L}$ ), $\mathrm{NaCl} 7.6 \mathrm{gm} / \mathrm{L}$, IPTG 0.2 $\mathrm{gm} / \mathrm{L}$ and MUG $0.1 \mathrm{gm} / \mathrm{L}$ ) with $E$. coli suspension

2. Comparison of recovery of colonies on media comprising $(\mathrm{NaCl} 7.6$ $\mathrm{gm} / \mathrm{L}$, IPTG $0.1 \mathrm{gm} / \mathrm{L}$ and $\mathrm{MUG} 0.1 \mathrm{gm} / \mathrm{L}),(\mathrm{NaCl} 7.6 \mathrm{gm} / \mathrm{L}$, IPTG 0.15 $\mathrm{gm} / \mathrm{L}$ and MUG $0.1 \mathrm{gm} / \mathrm{L})$ and $(\mathrm{NaCl} 7.6 \mathrm{gm} / \mathrm{L}$, IPTG $0.2 \mathrm{gm} / \mathrm{L}$ and MUG $0.1 \mathrm{gm} / \mathrm{L}$ ) with $E$. coli suspension.

\section{RESULTS}

\section{COMPARISON OF COLONY RECOVERIES ON GELMAN BLACK AND WHITE} MEMBRANES WITH WATER-BATH INCUBATION USING E. COLI SUSPENSION

Number of experiments were performed on the medium to examine the recovery of colonies on Gelman White and Black membranes using E. coli suspension. Experimental conditions and protocols were as described as above and reading was taken only at 8 hours.

Table- 2: Water-bath Incubation with Pre-heating the Media

\begin{tabular}{|c|c|c|c|}
\hline No. of rep. (n) & Incubation time & $\begin{array}{c}\text { Black membrane } \\
\text { cfu/100 ml }\end{array}$ & $\begin{array}{c}\text { White membrane } \\
\text { cfu/100 ml }\end{array}$ \\
\hline 20 & 8 hours & 89.5 & 113.3 \\
\hline
\end{tabular}

COMPARISON OF COLONY RECOVERIES ON GELMAN BLACK AND WHITE MEMBRANES UNDER THE TOW INCUBATION CONDITIONS AT $44^{\circ} \mathrm{C}$

These experiments were carried out with the preheated medium in order to assess the importance of the incubation method using E. coli suspension. Experimental conditions and protocol were as explained above except readings were only taken at 8 hours. Furthermore, in these experiments, the Colilert method was used to compare the results.

Table- 2: Air and Water-Bath Incubation with Pre-Heating the Medium and Using E. Coli Suspension

\begin{tabular}{|c|c|l|c|c|c|}
\hline $\begin{array}{c}\text { No. of } \\
\text { Rep (n) }\end{array}$ & $\begin{array}{c}\text { Incubation } \\
\text { time }\end{array}$ & $\begin{array}{c}\text { Incubation } \\
\text { Condition }\end{array}$ & $\begin{array}{c}\text { Black } \\
\text { membrane } \\
\text { cfu/100 ml }\end{array}$ & $\begin{array}{c}\text { White } \\
\text { membrane } \\
\text { cfu/q00 ml }\end{array}$ & $\begin{array}{c}\text { Colilert } \\
\text { MPN }\end{array}$ \\
\hline 80 & 8 hours & $\begin{array}{l}\text { Air } \\
\text { incubation }\end{array}$ & 18.6 & 19.83 & 32.7 \\
\hline 80 & 8 hours & Water-bath & 9.94 & 11.85 & \\
\hline
\end{tabular}




\section{TAILORED MEDIA FOR THE DETECTION}

Key: Each figure represents the mean of given replicates (n).

\section{Bar Diagram}

The results show again that overall numbers of recovery with the Gelman Black membrane are lower than those with the Gelman White membrane. The colonies were brighter in preheated media incubated at $44^{\circ} \mathrm{C}$ in an air incubator than in a water bath under the same conditions however, as is evident by the results, the new protocol is appreciably inferior to the Colilert method for the estimation of $E$. coli.

Table- 3: Evaluation of the Performance of Recovery of Colonies on Different Membranes (Incubation time 8 hours at $44^{\circ} \mathrm{C}$ )

\begin{tabular}{|c|c|c|c|c|c|c|c|}
\hline $\begin{array}{c}\text { No. of } \\
\text { rep (n) }\end{array}$ & $\begin{array}{c}\text { Gel. White } \\
\text { membrane }\end{array}$ & $\begin{array}{c}\text { Gel. Black } \\
\text { membrane }\end{array}$ & $\begin{array}{c}\text { Whatman } \\
\text { membrane }\end{array}$ & $\begin{array}{c}\text { Sortorius } \\
\text { membrane }\end{array}$ & $\begin{array}{c}\text { Millipore } \\
\text { membrane }\end{array}$ & $\begin{array}{c}\text { Corning } \\
\text { membrane }\end{array}$ & $\begin{array}{c}\text { Colilert } \\
\text { MPN }\end{array}$ \\
\hline 37 & 11.18 & 10.0 & 9.8 & 8.1 & 8.2 & 9.6 & 10.8 \\
\hline
\end{tabular}

Note: Each figure represents the mean no of colonies recovered for given replicates (n)

The results show that Gelman white membrane recovered the highest number of colonies of all the membranes examined. The intensity of brightness and size of the colonies was also better in Gelman white membrane than for the other membranes. The grid lines of the Sortorius membrane and uneven surface hindered the measurements and made the colonies difficult to read. In Whatmann and Millipore membrane the recovery of colonies were tiny, less bright and some had an orangy appearance. In the Corning membrane the fluorescence was fiffuse and difficult to read. Compared with Colilert, the recovery was reasonable.

The variation in the concentrations of ingredients in the base medium is given below Table: 
TRIBHUVAN UNIVERSITY JOURNAL, VOL. XXIV, NO. 1,

Table- 4:

\begin{tabular}{|c|c|c|}
\hline Symbol & Ingredients & $\mathrm{Gm} / \mathrm{L}$ \\
\hline A & No extra ingredient & Normal \\
\hline B & $\mathrm{NaCl}$ & $7.6 \mathrm{gm} / \mathrm{L}$ \\
\hline C & $\mathrm{NaCl}$ & $4.8 \mathrm{gm} / \mathrm{L}$ \\
\hline$D$ & $\mathrm{NaCl}$ & $2.4 \mathrm{gm} / \mathrm{L}$ \\
\hline E & $\mathrm{KCl}$ & $96 \mathrm{gm} / \mathrm{L}$ \\
\hline F & $\mathrm{KCl}$ & $6.4 \mathrm{gm} / \mathrm{L}$ \\
\hline$G$ & $\mathrm{KCl}$ & $3.2 \mathrm{gm} / \mathrm{L}$ \\
\hline $\mathrm{H}$ & Lactose & $30 \mathrm{gm} / \mathrm{L}$ \\
\hline
\end{tabular}

\section{Bar Diagram}

It is evident after 8 hours incubation, medium- $\mathrm{B}$ with $\mathrm{NaCl} 7.6 \mathrm{gm} / \mathrm{L}$ had recovered the highest number of colonies and medium- $\mathrm{H}$ with lactose $30 \mathrm{gm} / \mathrm{L}$ had recovered the least number of colonies. After 24 hours of incubation, medium-B still had the highest number of colonies by an appreciable margin compared to the Envirofast medium. Furthermore the results at 8 hours incubation were comparable with those from the Colilert method and superior to this type of analysis at 24 hours incubation. Indeed at 24 hours incubation the media A, C, D, E, F, G, H, gave closely similar results. The significant difference between the Envirofast medium and the other media is that the Envirofast medium contained bile salts and sodium lauryl sulphate but the other media did not. The absent of these ingredients clearly yields a better recovery at both 8 and 24 hours incubation periods. Furthermore while assessing the colonies it was observed that the Envirofast medium itself fluoresced more than prepared medium under UV light $(365 \mathrm{~nm})$. Because of the effect, after 24 hours incubation it was difficult to count the colonies recovered, but with great care all colonies were successfully counted. 
From the experiments, it is evident that the media containing varying proportions of the electrolystes $\mathrm{NaCl}$ and $\mathrm{KCl}$ without bile salts and sodium lauryl sulphate were significantly better than the commercially available Envirofast medium and the analysis using the Coliert method.

EVALUATION OF THE EFFECT OF THE ADDITIO OF IPTG AND MUGal ON THE BASE MEDIUM WITH PRE AND POST AUTOCLAVING

An evaluation have been made of the effect of IPTG and MUGal on the base medium with pre and post autoclaving using fresh $e$. coli suspension at nominal dilution. The MUGal solution was prepared in dimethyl sulphoxide (DMSO) solvent.

EVALUATION OF RECOVERY OF COLONY ON MEDIUM NaCl $7.6 \mathrm{gm} / \mathrm{L}$ WITH ALTERING CONCENTRATION OF IPTG

Comparison of recovery of colonies on medium

(1) $\mathrm{NaCl} 7.6 \mathrm{gm} / \mathrm{L}$, and IPTG $0.1 \mathrm{gm} / \mathrm{L},-\mathrm{A}$

(2) $\mathrm{NaCl} 7.6 \mathrm{gm} / \mathrm{L}$, and IPTG $0.2 \mathrm{gm} / \mathrm{L},-\mathrm{B}$

(3) $\mathrm{KCl} 7.6 \mathrm{gm} / \mathrm{L}$, IPTG $0.1 \mathrm{gm} / \mathrm{L},-\mathrm{C}$

(4) $\mathrm{KCl} 9.6 \mathrm{gm} / \mathrm{L}$, IPTG $0.1 \mathrm{gm} / \mathrm{L},-\mathrm{D}$

\begin{tabular}{|c|c|c|c|c|c|c|}
\hline $\begin{array}{c}\text { No. of } \\
\text { rep. (n) }\end{array}$ & $\begin{array}{c}\text { Inc. } \\
\text { Time }\end{array}$ & A & B & C & D & $\begin{array}{c}\text { Colilert } \\
\text { MPN }\end{array}$ \\
\hline $5^{\text {a }}$ & 8 hrs. & 47.0 & 17.2 & 36.4 & 40.6 & 22 hrs. \\
\hline & 24 hrs. & 56.6 & 42.2 & 42.6 & 46.6 & 49.0 \\
\hline
\end{tabular}

${ }^{\mathrm{a}}=$ Fresh E. coli suspension at nominal dilution $10^{2} / 100 \mathrm{ml}$

Incubator temp. $=41^{\circ} \mathrm{C}$, Membrane $=$ Gelman White

The results of fresh E.coli suspension showed that the medium comprising $\mathrm{NaCl} 7.6 \mathrm{gm} / \mathrm{L}$, with IPTG $0.1 \mathrm{gm} / \mathrm{L}$ recovered highest number of colonies.The medium comprising $\mathrm{NaCl} 7.6 \mathrm{gm} / \mathrm{L}$, with IPTG $0.2 \mathrm{gm} \mathrm{I} / \mathrm{L}$ recovered least number of colonies at the same incubation time.

As compared to the colilert the recovery was reasonable in the new medium.

Results have proved that the medium containing $\mathrm{NaCl} 7.6 \mathrm{gm} / \mathrm{L}$ is found better than other medium. No bile salts and sodium lauryl sulphate were added in the medium. The medium $\mathrm{NaCl} 7.6 \mathrm{gm} / \mathrm{L}$ with IPTG $0.2 \mathrm{gm} / \mathrm{L}$ is not feasible for the recovery of colony.

EFFECT OF VARYING CONCENTRATION OF IPTG ON MEDIUM NaCI $7.6 \mathrm{gm} / \mathrm{L}$

Comparision of recovery of colonies on medium:

(1) $7.6 \mathrm{gm} \mathrm{NaCl} / \mathrm{L}, 0.1 \mathrm{gm} \mathrm{IPTG} / \mathrm{L} \mathrm{L}-\mathrm{A}$

(2) $7.6 \mathrm{gm} \mathrm{NaCl} / \mathrm{L}, 0.15 \mathrm{gm} \mathrm{IPTG} / \mathrm{L}-\mathrm{B}$

(3) $7.6 \mathrm{gm} \mathrm{NaCl} / \mathrm{L}, 0.2 \mathrm{gm}$ IPTG/L $-\mathrm{C}$ 
TRIBHUVAN UNIVERSITY JOURNAL, VOL. XXIV, NO. 1,

The medium was prepared as described in section 7.15

\begin{tabular}{|c|c|c|c|c|c|c|c|}
\hline \multirow{2}{*}{$\begin{array}{c}\text { No. of } \\
\text { rep. (n) }\end{array}$} & \multicolumn{2}{|c|}{ Medium A } & \multicolumn{2}{c|}{ Medium B } & \multicolumn{2}{c|}{ Medium C } & Colilert \\
\cline { 2 - 8 } & 8 hrs & 24 hrs. & 8 hrs. & 24 hrs. & 8 hrs. & 24 hrs. & 22 hrs. \\
\hline $5^{\text {a }}$ & 2.8 & 4.6 & 1.0 & 3.2 & 0.4 & 3.2 & 9.3 \\
\hline
\end{tabular}

Key:

${ }^{\mathrm{a}}=$ Fresh $E$. coli suspension prepared at dilution $10^{1} / 100 \mathrm{ml}$ from net $10^{9} / \mathrm{ml}$ Incubator temp. $=41^{\circ} \mathrm{C}$

Membrane $=$ Gelman White

The results showed that the medium comprising $\mathrm{NaCl} 7.6 \mathrm{gm} / \mathrm{L}$ with IPTG $0.1 \mathrm{gm} / \mathrm{L}$ recovered highest number of colonies at 8 and 24 hours incubation compared to media comprising IPTG $0.15 \mathrm{gm} / \mathrm{L}$, IPTG $0.2 \mathrm{gm} / \mathrm{L}$. Colony was very tiny in the medium comprising IPTG $0.2 \mathrm{gm} / \mathrm{L}$ and was difficult to count. But with great care colonies were counted successfully.

As compared to Colilert there was under recovered in the media.

Overall optimum concentration of IPTG for the best recovery was found to be $0.1 \mathrm{gm} / \mathrm{L}$ and Sodium chloride $7.6 \mathrm{gm} / \mathrm{L}$. No bile salts and sodium lauryl sulphate is required.

\section{DISCUSSION}

As explained in the objective of the project, there is a need for a rapid method for the estimation of E. coli in drinking waters particularly where there are no adequate testing facilities in developing countries such as Nepal. This procedure would also be suitable in emergencies where there was an urgent need 


\section{TAILORED MEDIA FOR THE DETECTION}

to determine water quality. In order to research such a method for a routine procedure, various experimental investigations were carried out under different conditions to detect coliforms and faecal coliforms in water samples.

The present formulations and protocol currently is not ideal to reliable routine or emergency method for a rapid assessment of the water quality because there were under recovered of stressed E. coli from 8-24 hours results. But from the early results it was decided that 8 hours would be the optimum time.

During the working procedure two main membranes (Gelman Black and Gelman White) were compared. The statistical significance test shows that there is significant difference between these membranes $(P<0.05)$. The results have shown that there is under recovery in the black membranes as compared to the white membranes.

The results have been compared with the Colilert method, it was also important to enumerate accurate number of colonies in the membrane, however, on some membranes colonies were small and ill-defined and they were difficult to count. However by exercising great care and attention reliable counts were achieved. The results were taken after 6-8 hours initially. During this period it was hoped that all wold be isolated.

The proposed methods for the detection of E. coli are based on $\beta$ glucuronidase activity, using the flurogenic substrate MUG. The enzyme $\beta$ glucuronidase produced by the E. coli cleaved the MUG and forms fluorescent substance 4-methylumbelliferone. This fluorescence is easy to identify under long wave length ultra violet (UV) light. The results confirm that assaying for the enzyme $\beta$-glucuronidase utilizing the MUG substrate is an accurate method for the detection of $E$. coli in the water samples. $94.4 \%$ of $E$. coli can be detected by using MUG substrate and $4 \%$ were true anaerogenic strains of $E$. coli which did not produce in any of the conventional lactose fermentation media at $44^{\circ} \mathrm{C}$ (Lois C. Shadix et al., 1993). E.coli has always been a specific indicator of fecal pollution which can be detected by rapid method with accuracy and specificity. In the past, identification of $E$. coli had been laborious and time consuming. Recent developments in substrate technology have simplified the direct detection of $E$. coli within 18 hours. The new formulation protocol has been successful for detecting $E$. coli rather more rapidly within 8 hours.

A large survey were performed on six different membranes having same pore size were also tested with different spiked samples at same concentration. Gelman White memberane was found better than other membrane. It was also found that the intensity of brightness and size of the colonies were also bigger in White membrane. In Whatmann and Millipore the recovery of colonies were tiny, less bright and some had orangy apperance. In corning membrane the fluorescence was diffuse and was difficult to count the colonies. Thus almost allexperimental works Gelman White membrane have been used. All results have been compared with the Colilert.

New protocols comprised the ingredient fluorogen 1methylumbellifery1- $\beta$-D-galactopyranoside (MUGal) and isopropyl- $\beta$-D- 
TRIBHUVAN UNIVERSITY JOURNAL, VOL. XXIV, NO. 1,

thiogalactopyranoside (IPTG) with varying concentration of $\mathrm{NaCl}$ and $\mathrm{KCl}$ have been tested to check the performances to detect E. coli and coliform. The substrate (MUGal) is cleaved by enzyme $\beta$-glucuronidase which is produced by $E$. coli. The IPTG induced inside the cell and enhanced the $E$. coli for growth in a short incubation time. Especially IPTG helps for the growth of stressed E. coli. The results Have proved that the media found to be sensitive, selective and specific and have low false positive and false negative rates. Chromogens and fluorogens, substrate that produce colour and fluorescence, respectively upon cleavage by a specific enzyme have been used for many years to detect and identify the coliform bacteria, including the fecal pollution indicator E. coli. Compounds such as o-nitrophenyl- $\beta$-D-galactopyranoside (OPNG), pnitrophenyl- $\beta$-D-galactopyranoside (PNPG) and 4-methylumbelliferyl- $\beta$-Dgalactopyranoside (MUGal) have been included in a variety of media to demonstrate the presence an enzyme produced by $E$. coli and coliforms. Chromogens, such as indoxyl- $\beta$-D-glucuronide (IBDG) and 5-bromo-4-chloro-3indolyl- $\beta$-D-glucuronide (X-Gluc), have also been used to detect and enumerate E. coli in water sample (Brenner Kristen P., et al., 1993).

$\mathrm{Na}^{+}$and $\mathrm{K}^{+}$ions are very essential for the growth of $E$. coli. They are the nutrients, but their excess amount will have the adverse effect for the growth.

It has been found that the medium containing $7.6 \mathrm{gm} \mathrm{NaCl} / \mathrm{L}$ with 0.1 $\mathrm{gm} \mathrm{MUGal} / \mathrm{L}$ and $0.1 \mathrm{gm} \mathrm{IPTG/L}$ recovered the highest number of colonies after 8 hours incubation. Statistical analysis has shown that there is significance difference with the media containing 30 gm lactose/L only $(P<0.05)$ but there were no significance difference between the media at varying concentration of $\mathrm{NaCl}$ and $\mathrm{KCl} .(P>0.05)$.

A large study was also conducted on the media at varying concentratio of IPTG. It has been found that the media comprising $0.1 \mathrm{gm} \mathrm{IPTG/L} \mathrm{recovered}$ highest number of colonies than the media comprising $0.15 \mathrm{gm} \mathrm{IPTG/L}$ and 0.2 gm IPTG/L. The recovery increased as the concentration of IPTG decreased. In other word, recovery is inversely proportional to concentration of IPTG/L.

\section{Recovery $\alpha 1 /$ concentration of IPTG/L}

The new formulations were not completely without problems. In some plates of the new formulations protocol the colonies were tiny, however the colonies were easily enumerated and some of the agar plates were themselves fluorescence under UV light.

In conclusion, the new formulations which have been designed in the laboratory are easy to prepare, perform and interpret the result in a short incubation period. They could be reliable and rapid method for detecting E. coli and coliform from several types water samples.

The activity of the enzyme $\beta$-glucuronidase and $\beta$-galactosidase with substrate were found useful for detecting $E$. coli and coliforms in the water samples. 


\section{TAILORED MEDIA FOR THE DETECTION}

These methods could be used for detection E. coli in drinking water where there are no adequate testing facilities and would also be suitable in emergencies where there was an urgent need to determine the water quality.

\section{WORKS CITED}

ANON (1994). The microbiology of waterm, Part 1, Drnking Wager, Report 71, HMSO.

APHA (1992). Standard methods for the Examination of water and waste water, $18^{\text {th }}$ edn. Washington DC: American Public Health Association.

Berger, S.A. (1994). Increased protection afforded by the defined substrate technology Colilert system by its ability to detect Shigella $\beta$-glucuronidase. Letters in Applied Microbiology, Vol. 19: 53-56.

Bradley, D.J. (1993). Human tropical diseases in a changing environment, in Environmental Change and Human Health, Wiley, Chichester, Ciba Foundation Symposium 171: 146-70.

Brenner, Kristen P, Rankin, Clifford C, Roybal, Yvette R., Stelma, Gerard N., Stelma, J.R., Scarpino, Pasquale V. \& Dufour, Alfred P. (1993). New Medium for the Simultaneous Detectioj of Total Coliforms and Escherichia coli in water. Applied and Environmental Microbiology, Nov., Vol. 59, No. 11, 3534-3544.

Cabelli, V. (1978). New standards for enteric bacteria, in water Pollution Microbiology, Vol. 2 (ed. R. Mitchell), Wiley-Interscience, New York, pp. 233-73.

Ciebin, B.W., Brodsky, M.H., Eddington, R., Horsnell, G., Choney, A., Palmater, G., Ley, A., Joshi R. \& Shears, G. (1995). Comparative Evaluation of modified m-FC and m-TEC Media for Membrane Filter Enumeratio of Escherichia coli in water. Applied and Environmental Microbiology, Nov., Vol. 61, 3940-3942.

Gleeson, C. \& Gray, No. (1997). The coliforms Index and Waterborne Disease, problem of microbial drinking water assessment.

Colquhoun, K.O., Timms, S. \& Fricker C.R. (1995). Detection of Escherichia coli in potable water using direct impedance technology. J. Appl. Bact. 79, 635-39.

Department of the Environment (1994a). The microbiology of water 1994: Part I Drinking water. Reports on the Public Health and the Medical Subjects No. 71 Methods for the Examinatio of Water and Associated Materials, HMSO, London. 